\title{
Yield and grape quality of three red grapevine cultivars (Vitis vinifera L.) in relation to altimetry
}

\author{
Luca Mercenaro*, Ana Fernandes de Oliveira, Massimiliano Cocco, and Giovanni Nieddu \\ Department of Agriculture, University of Sassari, Viale Italia 39, 07100 Sassari (Italy)
}

\begin{abstract}
Environment has a great impact on berry composition. In this context we investigated the quality of extremely widespread grape varieties in Sardinia, cvs. Cannonau, Bovale sardo and Monica, cultivated at different altitudes. The work was conducted in a two-year period in two vineyards located respectively at 500 and 700 meters above sea level. Viticultural model and cultivation practices were the same for both vineyards. The following measurements were noted: (i) main phenological phases, (ii) yield and its components, (iii) must quality from veraison to harvest, and (iv) anthocyanin qualitative profiles at harvest. At higher altitude the phenological phases are delayed. Yield was not statistically influenced by altitude. The ripening of the main technological parameters, although similar among the vineyards, suggests that the effects of the different altitude are clear, but they vary according to year and are cultivar dependent. In cv. Cannonau, higher altitude promoted higher total soluble solids. The extractable anthocyanins were not influenced by altitude, although in all tested varieties the higher altitude favored a decrease in the ratio between non-acylated and acylated anthocyanins.
\end{abstract}

\section{Introduction}

Mandrolisai is one of the most important viticultural districts in Sardinia. Currently the viticulture in this area, located in the centre of Sardinia, is located between 300 and 900 meters above sea level. The soils derived from fragmentation of the parent rock of granite or schist origin, are generally sandy, loose and freely-draining, characterized by an acidic or sub acid $\mathrm{pH}$, poor in nitrogen and phosphorus but rich in potassium. In this area, the vine cultivation covers a surface of just over 1200 hectares and yield per hectare fluctuates around $5 \mathrm{t}$.

Regarding the ampelographic platform, the red grapevines predominate and in particular the cvs. Bovale sardo, Cannonau and Monica. Since 1981 the DOC designation Mandrolisai has been assigned totypical wines produced in this viticultural district.

In order to use this appelation of origin it is necessary that, in addition to respecting the yield limits imposed by the product specification itself, the "Mandrolisai" wines must be obtained from the grapes coming from the vines present in the vineyards in a well-defined proportion: cv. Bovale sardo (locally called Muristellu) no less than 35\% while Cannonau and Monica must be present respectively from $20 \%$ to $35 \% ; 10 \%$ of others grape are also allowed.

Although viticulture in the Mandrolisai district has always been located between 300 and 900 meters above sea level, in the last 20 years there has been a gradual change in vineyard location. The new sites chosen are mainly situated at higher altitudes, between 700 and 900 meters above sea level. The local grape growers justify this variation in altitude mainly to avoid the frost, which is increasingly frequent in this area.

Vineyard altitude can result in variation in temperature, solar radiation and ultraviolet radiation, and these climatic factors have been demonstrated to have a strong effect on phenology as well as several chemical parameters of the berry [1]. Budburst and flowering were later in vineyards at higher altitudes on cv. Mencia in Galizia [2]. Stefanini et al. [3] showed that sugar content decreased with increasing altitude of cultivation. The same conclusions were reported by Bertamini et al. [4] that underlined a positive relation between titratable acidity and altitude. Working on Sangiovese, Storchi e Mattii [5] reported that photosynthetic activity and leaf water potential were greater at higher altitudes while no effect on total soluble solids was found. Little information is available on the mechanical properties of the berries; Nedelkovski et al. [6] report that the different altitudes did not have a significant effect on the epidermal layer thickness. Contrarily, more than a few studies have examined the effects of vineyard altitude on phenolic and aromatic compound in grapes and wines from different vine growing areas. In an experimental trial carried out in Douro valley in Portugal, on Touriga Francesa and Touriga National, low altitude seemed to be an important factor favoring the biosynthesis of some phenol compounds [7]. In wine, higher altitude

*Corresponding author: mercenar@,uniss.it 
promoted the largest amount of total anthocyanin aminoglycosides [8], while, although the numbers of volatile compounds increased with higer altitudes, the concentration of the total volatiles decreased [9]. Although some information related to bio-agronomic characteristics of these varieties is already present in the literature [10, 11], with the aim of increasing the knowledge on the influence that altitude can have on the quality of the berries, this work sought toinvestigate the differences that the altitude of cultivation could have on three traditional varieties from Sardinia that, blended together, give origin to one of the most characteristic Sardinian wines.

\section{Material and Methods}

\subsection{Study site and experimental design}

The observations were carried out in 2009-2010 in two private vineyards located in Atzara (NU). The vineyards were located at different altitudes, respectively at 500 and 700 meters above sea level. Both vineyards, planted in 2002 and 2004 respectively and grafted onto 1103 Paulsen, were bilateral cordon trained with a very short pruning in order to keep production within 4 and $5 \mathrm{t}$ per hectare, with a plant density of 5000 vines per hectare. Vineyard management practices were those of common use in Mediterranean environments, where the soils are frequently tilled and the use of cover cropsand irrigation are not ordinary. As required by the product specification (appellation of origin DOC), in both vineyards, the cultivars were planted in the following proportion: cv. Cannonau 35\%, cv. Monica 30\% and cv. Bovale sardo $35 \%$. Before starting the experiment, each vineyard was divided into three sectors of three adjoining rows, that represented our plots. In every single plot, 30 vines of each variety were identified and tagged. All the measurements reported were conducted only on tagged vines. Following this strategy, the present study was conducted in a randomized complete block design with three replications.

\subsection{Vine growth, yield berry and juice analysis}

Phenological phases have been recorded periodically, according to the $\mathrm{BBCH}$ scale. Each year, the evolution of fruit composition was assessed on 600 berries randomly collected. Sampling days were the $7^{\text {th }}, 14^{\text {th }}, 22^{\text {nd }}$ and $29^{\text {th }}$ of September in the first year and the $21^{\text {st }}$ and $27^{\text {th }}$ of September and $5^{\text {th }}$ of October in the second year of observation. Berries were weighed and crushed, and total soluble solids ( $\left.{ }^{\circ} \mathrm{Brix}\right), \mathrm{pH}$ and titratable acidity of juice were determined in accordance with the procedures of the Organisation Internationale de la Vigne et du Vin. Total anthocyanins and polyphenols, as well as their extractable components, were evaluated following the methodology proposed by Mattivi et al., [12]. At 12\% hydro alcoholic solution of ethyl alcohol with $5 \mathrm{~g} / \mathrm{L}$ of tartaric acid neutralised to $\mathrm{pH} 3$ with $\mathrm{NaOH}$, and supplemented with $100 \mathrm{mg} / \mathrm{L}$ of potassium metabisulphite, was prepared for the polyphenol extraction. Skins and seeds from $200 \mathrm{~g}$ of berries were manually separated and poured into two flasks, each containing $200 \mathrm{~mL}$ of hydro alcoholic solution. The flasks were put in a stove at $30^{\circ} \mathrm{C}$ for 5 days; each flask was stirred once daily. At the end of the extraction, the seed extract was directly poured into a 260 $\mathrm{mL}$ bottle, while the skin extract, obtained by gravity and manual pressing of the skins, was centrifuged for $8 \mathrm{~min}$ at $8000 \mathrm{rpm}$ to remove the lees and then poured into a 260 $\mathrm{mL}$ bottle. The bottles were filled with the hydro alcoholic solution, closed with a screw cap and stored at $4^{\circ} \mathrm{C}$ until the analysis. Spectrophotometric determinations were carried out on the extracts according to the methods of $\mathrm{Di}$ Stefano et al. [13], which allow isolation of the phenolic compounds on a Sep-Pak C18 cartridge to eliminate interference due to salts, sugars and proteins (HP 8453 UV-VIS spectrophotometer, Palo Alto, CA).

The HPLC system for the analysis of monomeric anthocyanins consisted of an Agilent model 1100HPLC, equipped with a binary pump, an autosampler injector, a degasser, a photodiode array (DAD) detector, controlled by a workstation (version 4) (Agilent Technologies, Santa Clara, CA, USA) [14]. Anthocyanins were separated on a Phenomenex Synergi $4 \mu \mathrm{m}$ Max-RP 80A, LC $(250 \times 4.60$ $\mathrm{mm}$ ) column (Phenomenex, Torrance, CA, USA). The eluents used were (i) $\mathrm{H}_{2} \mathrm{O}: \mathrm{CH}_{3} \mathrm{CN}: \mathrm{HCOOH}(87: 3: 10$ $\mathrm{v} / \mathrm{v}$ ) and (ii) $\mathrm{H}_{2} \mathrm{O}: \mathrm{CH}_{3} \mathrm{CN}: \mathrm{HCOOH}(40: 50: 10 \mathrm{v} / \mathrm{v})$. The anthocyanins were eluted at a rate of $0.5 \mathrm{~mL} / \mathrm{min}$ and detected at $520 \mathrm{~nm}$. Monomeric anthocyanins were identified by peak area integration at $520 \mathrm{~nm}$ using malvidin-3-glucoside as a standard. The concentration of individual anthocyanins was expressed as a proportion of the total peak area of all the anthocyanins.

For each cultivar, vine yield and yield elements (cluster and berry weights, and number of clusters per vine) were determined by weighing ten clusters randomly picked for each replicate and ten berries randomly picked from each cluster.

\subsection{Statistical analysis}

For each cultivar, the data collected were statistically analyzed by one-way Anova, separately for each observation year, using the SPSS 16 statistical package (SPSS, Chicago, IL, USA).The least significant difference (LSD) test was performed with the same statistical package to compare means and detect significant differences between vineyards altitude at $95 \%$ confidence level.

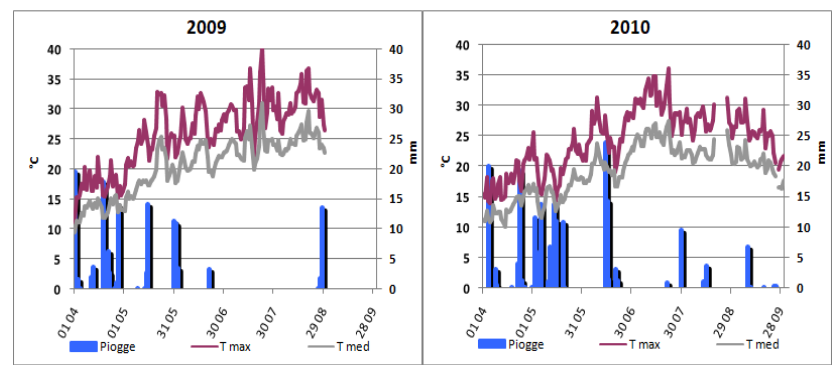

Fig. 1. Meteorological conditions between 2009 and 2010 in Atzara (NU), Sardinia.

\section{Results}




\subsection{Meteorological trends and vine phenology during the 2-year period}

Observing the meteorological trend of the two experimental years (Figure 1) it is clear that 2009 was characterized by the absence of rains except for one rainy event occurring at the end of August. Air temperatures, medium and maximum, were higher than in the following year, the latter being cooler and more rainy. The main results of the two-year experimentation show that phenological stages are delayed at higher altitude, especially bud burst and flowering. This delay is much more evident in the first year of investigation than in the second (Figure 2). With regard to the differences between varieties, regardless of altitude and vintage, cv. Cannonau were reached each of the phenological stages before cvs. Monica and Bovale sardo.

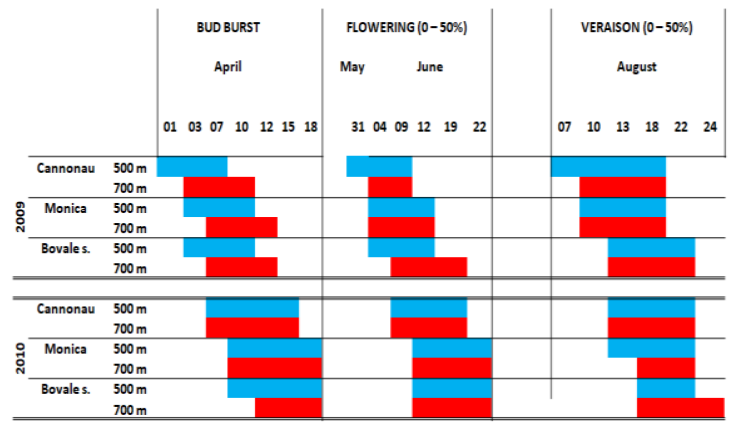

Fig 2. Timing of occurrence of the main phenophases in the two vineyards in 2009 and 2010 on cvs. Monica, Cannonau and Bovale sardo cultivated at different altitude

\subsection{Yield and its component}

Vine yield and its components have been assessed at harvest (table 1). Vineyards at higher sites typically showed a higher yield per plant due to clusters being heavier and more numerous. However, the statistical analysis did not confirm this greater productivity found in the vineyard at 700 meters above sea level. In both vineyards, yields for the 2010 vintage were higher compared to 2009 due to a greater number of clusters per plant. With regard to differences between varieties, cv. Monica was the most productive of the three, due to heavier clusters, on average.

\subsection{Must quality}

Sugar and acidity accumulation trends are shown in Figure 3. Independently from site and year, the technological characteristics of each cultivar were confirmed: the Cannonau is the variety that, normally, develops higher sugar concentration while the Monica cultivar is the variety with the lowest total acidity.

With regards to synthesis and accumulation of total soluble solids, in the first year of survey, the three varieties showed different behaviors. While in cv. Cannonau TSS was always statistically higher in the vineyard located at 700 meters, in the cv. Bovale sardo we noted no influence of altitude on the sugar level. Focusing on cv. Monica, the altitude of the vineyard had a significant effect on the accumulation of sugar; at harvest the grape berries from the lower altitude vineyard contained a higher sugar concentration. On the contrary, the titratable acidity was not influenced by the altitude in any of the varieties.

In the following year, grapes grown in the lower altitude vineyard have lower titratable acidity, while, only in cv. Cannonau, the grapes grown at at 700 meters showed higher TSS concentration.

Total polyphenols (data not shown) were negatively affected by altitude only at harvest. However, this reduction was not always statistically significant. The lower altitude promoted a greater synthesis and accumulation of anthocyanins in cvs. Bovale sardo and Monica, but only in 2010 (Figure 4). Extractable polyphenols (data not shown) and extractable anthocyanins did not appear to have been influenced by altitude.

The anthocyanic component of the three varieties, regardless of site and vintage, shows that cv. Bovale sardo is responsible for a majority of the color of the blended Mandrolisai wine. Cannonau [15] and Monica are in fact genetically less capable of developing anthocyanins, both total and extractable.

The anthocyanin qualitative profile, which emerged from each cultivar's characteristic varietal profile, includes the 5 non-acylated anthocyanins and acylated anthocyanins in the acetyl and coumaroyl forms. On average, the Cannonau grape contained over $56 \%$ of malvidin 3monoglucoside and $13.6 \%$ of peonidine 3 monoglucoside, while the other non-acylated forms do not exceed $10 \%$. Among the acylated anthocyanins, the amount of malvidin 3-p-coumaroyl glusoside was about $5.5 \%$ and the total content in acylated anthocyanins was less than $9 \%$ (Table 2).

Table 1. Yield and its components detected at harvest. Values reported represent the mean of three replication following by \pm standard deviation.

\begin{tabular}{|c|c|c|c|c|c|c|}
\hline Cultivar & Year & \begin{tabular}{|c} 
Site \\
\\
$m$ \\
above \\
sea \\
level
\end{tabular} & $\begin{array}{r}\text { Yield } \\
\text { kg }\end{array}$ & $\begin{array}{c}\text { Bunch } \\
n^{\circ}\end{array}$ & $\begin{array}{c}\text { Bunch } \\
\text { weight } \\
\quad g\end{array}$ & $\begin{array}{c}\text { Berry } \\
\text { weight } \\
\quad g\end{array}$ \\
\hline \multirow{4}{*}{ Monica } & \multirow{2}{*}{2009} & 500 & $\begin{array}{c}\mathbf{1 . 7 7} \pm \\
0.49\end{array}$ & $\begin{array}{c}\mathbf{5 . 0 9} \pm \\
2.26\end{array}$ & $\begin{array}{c}\mathbf{3 1 4 . 6} \pm \\
55.4\end{array}$ & $\begin{array}{c}\mathbf{2 . 7 2} \pm \\
0.21\end{array}$ \\
\hline & & 700 & $\begin{array}{c}\mathbf{2 . 4 2} \pm \\
0.84 \\
\end{array}$ & $\begin{array}{c}\mathbf{5 . 3 6} \pm \\
2.50 \\
\end{array}$ & $\begin{array}{c}\mathbf{3 6 5 . 8} \pm \\
123.0 \\
\end{array}$ & $\begin{array}{c}3.29 \pm \\
0.33\end{array}$ \\
\hline & \multirow{2}{*}{2010} & 500 & $\begin{array}{c}\mathbf{1 . 9 5} \pm \\
0.25\end{array}$ & $\begin{array}{c}\mathbf{6 . 2 0} \pm \\
1.32\end{array}$ & $\begin{array}{c}\mathbf{3 0 9 . 3} \pm \\
57.3\end{array}$ & $\begin{array}{c}\mathbf{2 . 3 5} \pm \\
0.40\end{array}$ \\
\hline & & 700 & $\begin{array}{c}\mathbf{2 . 3 0} \pm \\
0.28 \\
\end{array}$ & $\begin{array}{c}\mathbf{7 . 4 2} \pm \\
1.85 \\
\end{array}$ & $\begin{array}{c}\mathbf{3 6 1 . 7} \pm \\
145.7 \\
\end{array}$ & $\begin{array}{c}\mathbf{3 . 2 8} \pm \\
0.41 \\
\end{array}$ \\
\hline \multirow{4}{*}{ Cannonau } & \multirow{2}{*}{2009} & 500 & $\begin{array}{c}\mathbf{0 . 9 5} \pm \\
0.37\end{array}$ & $\begin{array}{c}\mathbf{5 . 6 0} \pm \\
3.33\end{array}$ & $\begin{array}{c}\mathbf{1 8 0 . 5} \\
\pm 65.5\end{array}$ & $\begin{array}{c}\mathbf{2 . 4 5} \pm \\
0.49\end{array}$ \\
\hline & & 700 & $\begin{array}{c}1.22 \\
0.45\end{array}$ & $\begin{array}{c}\mathbf{8 . 0 3} \pm \\
3 ., 59\end{array}$ & $\begin{array}{c}\mathbf{2 1 2 . 5}_{ \pm} \\
100.3\end{array}$ & $\begin{array}{c}\mathbf{2 . 3 2} \pm \\
0.74\end{array}$ \\
\hline & \multirow{2}{*}{2010} & 500 & $\begin{array}{c}\mathbf{1 . 1 8}_{ \pm} \\
0.32\end{array}$ & $\begin{array}{c}\mathbf{5 . 3 5}_{ \pm} \\
1.99 \\
\end{array}$ & $\begin{array}{c}\mathbf{2 0 0 . 5} \\
65.7 \\
\end{array}$ & $\begin{array}{c}\mathbf{1 . 8 2} \\
0.44 \\
\end{array}$ \\
\hline & & 700 & $\begin{array}{c}1.39 \pm \\
0.49 \\
\end{array}$ & $\begin{array}{c}\mathbf{6 . 2 1} \pm \\
2.44 \\
\end{array}$ & $\begin{array}{c}226.1 \\
99.4 \\
\end{array}$ & $\begin{array}{c}1.94 \\
0.62 \\
\end{array}$ \\
\hline \multirow{4}{*}{$\begin{array}{c}\text { Bovale } \\
\text { sardo }\end{array}$} & \multirow{2}{*}{2009} & 500 & $\begin{array}{c}\mathbf{1 . 0 1} \pm \\
0.50 \\
\end{array}$ & $\begin{array}{c}\mathbf{5 . 6 0} \pm \\
3.08 \\
\end{array}$ & $\begin{array}{c}\mathbf{1 7 9 . 4} \pm \\
78.1 \\
\end{array}$ & $\begin{array}{c}\mathbf{2 . 7 5} \pm \\
0.44 \\
\end{array}$ \\
\hline & & 700 & $\begin{array}{c}\mathbf{0 . 9 2} \pm \\
0.55 \\
\end{array}$ & $\begin{array}{c}\mathbf{5 . 8 0} \pm \\
2.74 \\
\end{array}$ & $\begin{array}{c}\mathbf{1 5 5 . 8} \pm \\
79.5 \\
\end{array}$ & $\begin{array}{c}\mathbf{2 . 4 6} \pm \\
0.29 \\
\end{array}$ \\
\hline & \multirow{2}{*}{2010} & 500 & $\begin{array}{c}\mathbf{1 . 1 5} \pm \\
0.46 \\
\end{array}$ & $\begin{array}{c}\mathbf{6 . 3 2} \pm \\
3.14 \\
\end{array}$ & $\begin{array}{c}\mathbf{1 8 9 . 9} \pm \\
88.1 \\
\end{array}$ & $\begin{array}{c}\mathbf{2 . 1 3} \pm \\
0.65 \\
\end{array}$ \\
\hline & & 700 & $\begin{array}{c}\mathbf{1 . 1 9} \pm \\
0.67 \\
\end{array}$ & $\begin{array}{c}\mathbf{5 . 8 4} \pm \\
3.77 \\
\end{array}$ & $\begin{array}{c}\mathbf{2 0 6 . 0} \pm \\
100.5 \\
\end{array}$ & $\begin{array}{c}\mathbf{2 . 0 5} \pm \\
0.50 \\
\end{array}$ \\
\hline
\end{tabular}



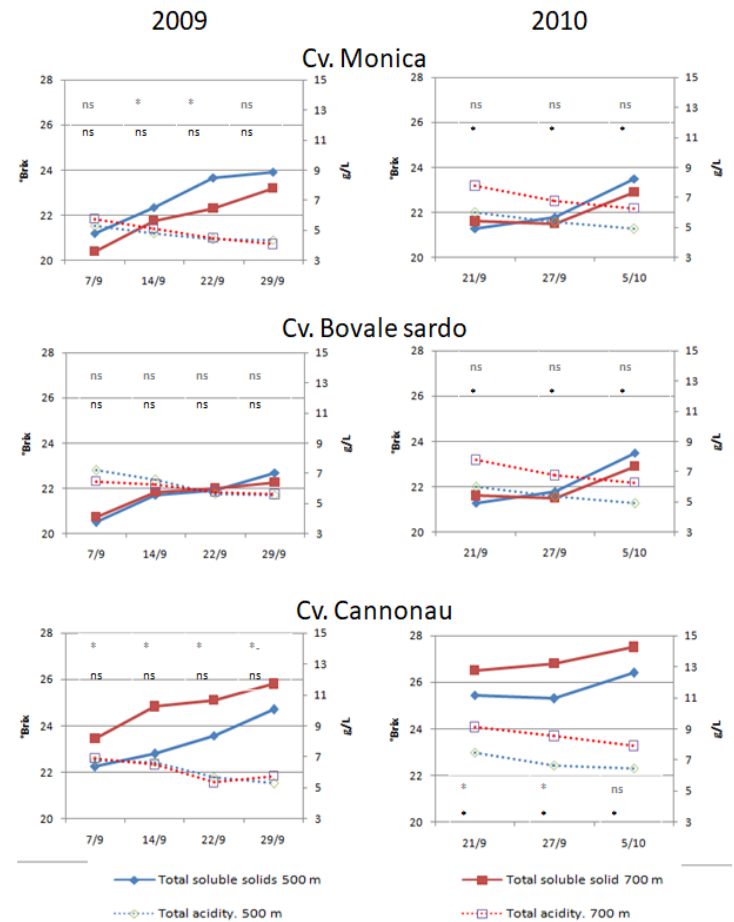

Fig. 3. Seasonal accumulation trend of total soluble solids and total acidity content in berry from veraison to harvest. Levels of significance (in grey for TSS and black for TA) are denoted by * $=\mathrm{P}<0.05$ or $\mathrm{ns}=$ not significant .
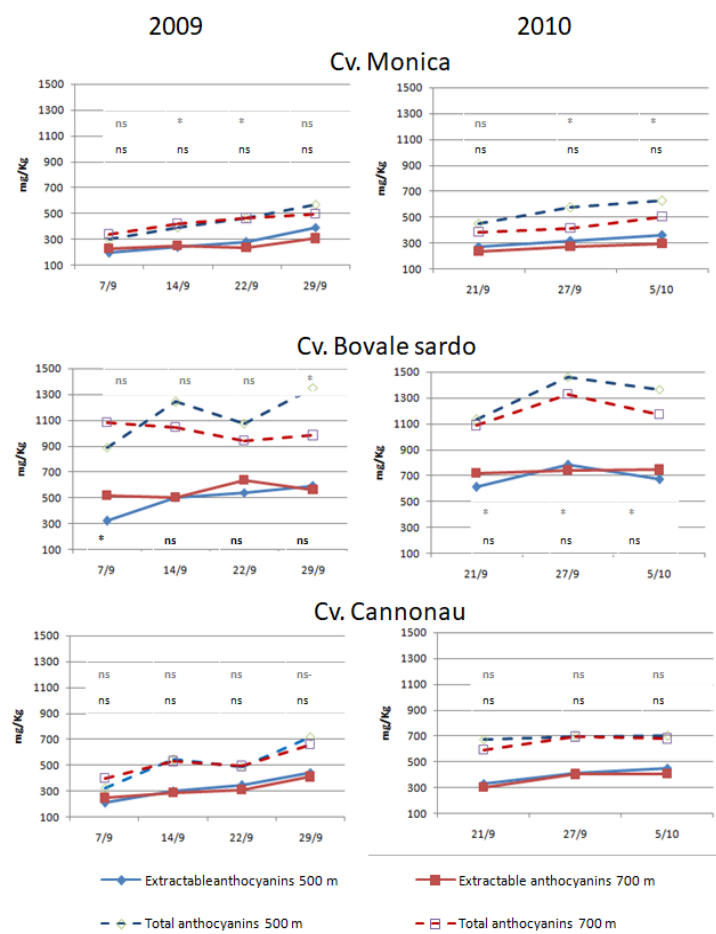

v. Cannonau

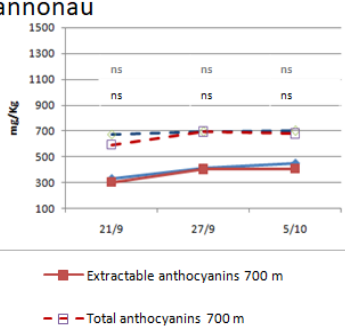

Fig. 4. Skin total and extractable anthocyanin content from veraison to harvest. Levels of significance (in grey for Total anthocyanins and black for Extractable anthocyanins) are denoted by $*=\mathrm{P}<0.05$ or $\mathrm{ns}=$ not significant.

A similar anthocyanin profile was found in cv. Monica; malvidin 3-monoglucoside reaches $42.6 \%$ while among the other non-acylated anthocyanins only cyaniding 3- monoglucoside showed levels lower than 10\%. The acylated formstogether reached $15.5 \%$ (Table 3 ).

The cv. Bovale sardo showed the lowest percentages of non-acylated anthocyanins, equal to $70.8 \%$ and the highest content in acylated anthocyanins, in particular the coumaroyl forms, which amounted to $23.3 \%$ (Table 4 ). With regards to relation between anthocyanins and altitude, statistical differences were found mainly in 2010 for some monomeric compound. It was possible to highlight a variation in the ratio of non-acylated and acylated forms, that decreases with increasing altitude. However, this variation appeared more marked in the cv. Bovale sardo than in the other two varieties compared.

\section{Discussion}

Global warming will affect all species in known as well as yet unknown ways, with certain regions such as the Mediterranean Basin and its major islands including Sardinia being particularly vulnerable to desertification [16].

Table 2. Percentages of monomeric non-acylated and acylated anthocyanins of cv. Cannonau. * indicate significant difference at $\mathrm{P} \leq 0.05$ and $\mathrm{ns}$ refers to non-significant differences among treatments.

\begin{tabular}{|c|c|c|c|c|c|c|c|}
\hline \multirow{2}{*}{\multicolumn{2}{|c|}{$\begin{array}{c}\text { Anthocyanins } \\
(\%)\end{array}$}} & \multicolumn{3}{|c|}{2009} & \multicolumn{3}{|c|}{2010} \\
\hline & & $\begin{array}{c}500 \\
\mathrm{~m} \\
\end{array}$ & $\begin{array}{c}700 \\
\mathrm{~m} \\
\end{array}$ & sig. & $\begin{array}{c}500 \\
\mathrm{~m} \\
\end{array}$ & $\begin{array}{c}700 \\
\mathrm{~m}\end{array}$ & sig. \\
\hline \multirow{6}{*}{$\begin{array}{l}\frac{0}{0} \\
0 \\
0 \\
0 \\
000 \\
0 \\
0 \\
\sum_{0}^{0} \\
n\end{array}$} & Delphinidin & 10.5 & 10.5 & ns & 8.8 & 8.7 & ns \\
\hline & Cyanidin & 1.5 & 2.7 & ns & 2.1 & 4 & ns \\
\hline & Petunidin & 9.1 & 9.2 & ns & 9.2 & 9 & ns \\
\hline & Peonidin & 10 & 12.2 & ns & 11.1 & 21.1 & $*$ \\
\hline & Malvidin & 58.2 & 55.5 & ns & 60.7 & 50.6 & * \\
\hline & Total & 89.3 & 90.1 & & 91.9 & 93.4 & \\
\hline \multirow{6}{*}{ 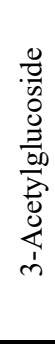 } & Delphinidin & n.d. & n.d. & & n.d. & n.d. & \\
\hline & Cyanidin & n.d. & n.d. & & n.d. & n.d. & \\
\hline & Petunidin & n.d. & n.d. & & n.d. & n.d. & \\
\hline & Peonidin & 0.2 & 0.3 & ns & 0.2 & 0.3 & ns \\
\hline & Malvidin & 1.7 & 1.6 & ns & 0.9 & 0.8 & ns \\
\hline & Total & 1.9 & 1.9 & & 1.1 & 1.1 & \\
\hline \multirow{6}{*}{ 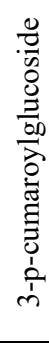 } & Delphinidin & n.d. & n.d. & & n.d. & n.d. & \\
\hline & Cyanidin & 0.2 & 0.3 & ns & 0.3 & 0.3 & ns \\
\hline & Petunidin & 0.3 & 0.3 & ns & 0.2 & 0.2 & ns \\
\hline & Peonidin & 1.4 & 1.5 & $\mathrm{~ns}$ & 1.3 & 1.4 & ns \\
\hline & Malvidin & 6.9 & 5.9 & ns & 5.2 & 3.6 & $*$ \\
\hline & Total & 8.8 & 8.0 & & 7.0 & 5.5 & \\
\hline
\end{tabular}


Table 3. Percentages of monomeric non-acylated and acylated anthocyanins of cv. Monica. * indicate significant difference at $\mathrm{P} \leq 0.05$ and ns refers to non-significant differences among treatments.

\begin{tabular}{|c|c|c|c|c|c|c|c|}
\hline \multicolumn{2}{|c|}{ Anthocyanins } & \multicolumn{3}{|c|}{2009} & \multicolumn{3}{|c|}{2010} \\
\hline & $(\%)$ & $\begin{array}{c}500 \\
\mathrm{~m}\end{array}$ & $\begin{array}{c}700 \\
\mathrm{~m}\end{array}$ & sig. & $\begin{array}{c}500 \\
\mathrm{~m}\end{array}$ & $\begin{array}{c}700 \\
\mathrm{~m}\end{array}$ & sig. \\
\hline \multirow{6}{*}{$\begin{array}{l}\frac{0}{0} \\
0 \\
0 \\
0 \\
0 \\
00 \\
0 \\
\sum_{0}^{0} \\
\infty\end{array}$} & Delphinidin & 16.8 & 16.8 & $\mathrm{~ns}$ & 9.3 & 13.5 & $*$ \\
\hline & Cyanidin & 3.7 & 6,3 & $\mathrm{~ns}$ & 6.5 & 4.5 & ns \\
\hline & Petunidin & 11.5 & 11,5 & ns & 8.8 & 11.5 & ns \\
\hline & Peonidin & 7,7 & 11,1 & $\mathrm{~ns}$ & 17.4 & 14.6 & $\mathrm{~ns}$ \\
\hline & Malvidin & 43.9 & 39,9 & ns & 44.0 & 42.7 & $\mathrm{~ns}$ \\
\hline & Total & 83.6 & 85,6 & & 86 & 86.8 & \\
\hline \multirow{6}{*}{ 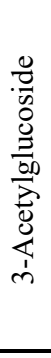 } & Delphinidin & n.d. & n.d. & & n.d. & n.d. & \\
\hline & Cyanidin & n.d. & n.d. & & n.d. & n.d. & \\
\hline & Petunidin & n.d. & n.d. & & n.d. & n.d. & \\
\hline & Peonidin & 0,2 & 0.3 & ns & 0.2 & 0.2 & ns \\
\hline & Malvidin & 5.8 & 5.8 & $\mathrm{~ns}$ & 2.9 & 4.7 & ns \\
\hline & Total & 6 & 6.1 & & 3.1 & 4.9 & \\
\hline \multirow{6}{*}{ 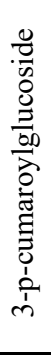 } & Delphinidin & 0.0 & 0.0 & ns & n.d. & 0.0 & \\
\hline & Cyanidin & 0.4 & 0.5 & $\mathrm{~ns}$ & 0.6 & 0,7 & ns \\
\hline & Petunidin & 0.3 & 0.2 & $\mathrm{~ns}$ & 0.3 & 0.2 & ns \\
\hline & Peonidin & 1.4 & 1.3 & $\mathrm{~ns}$ & 1.9 & 1.5 & $*$ \\
\hline & Malvidin & 8.3 & 6.3 & * & 8.1 & 6.0 & $*$ \\
\hline & Total & 10.4 & 8.3 & & 10.9 & 8.4 & \\
\hline
\end{tabular}

Nowadays the effects that the ongoing climate change is bringing to the wine industry system are well known. Increased temperatures result in advances in all of the phenological phases of the vine, so that harvest is nowadays anticipated by an average of 10-15 days compared to 1988 [17]. These changes are already affecting grape composition with observed changes in sugar and acidity concentrations. As with other compounds, such as polyphenols or aroma compounds, their relationships to environmental changes are more difficult to quantify [18]. Innovative management strategies of the canopy are tested in all the traditional viticultural areas, including the return to the use of autochthonous grapevines as well as the introduction of new varieties and/or rootstocks, aimed to compensate for the increase in evapotranspiration rates, all a direct consequence of temperature increases. Among the different strategies proposed to mitigate current climate change, shifting viticultural areas requires that the new locations have suitable soil and not increased frost risk or disease pressure..

In our study, the shift of the cultivation area of about 200 meters in elevation, allowed the three varieties to be cultivated in a place that, until just over 20 years ago, was considered not very suitable for viticultural purposes. The present work clearly shows that the influences of altitude on sugar accumulation is variety dependent. As a matter of fact, while previously observed by Storchi and Mattii on cv. Sangiovese in Tuscany [5], there are no influences of the altitude on the accumulation of sugar in the $\mathrm{cv}$. Bovale sardo, while in the cv. Monica we noted a decrease in the sugar level at higher altitude, as previous observed in Chardonnay in two Trentino districts [3] and more recently on Pinot noir in Sicily [19]. On the contrary, it is right to emphasize that the cv. Cannonau has shown significant sugar increases when grown at higher altitudes. In a zoning work conducted in another mountain area in Sardinia, Tomasi et al. [20], working on Cannonau grapes, noted that there was a close link between sugar content in berries and altitude: the greatest sugar accumulation was achieved at higher altitudes, perhaps where soil moisture and climatic conditions were more favorable to the sugar synthesis and accumulation.

Table 4. Percentages of monomeric non-acylated and acylated anthocyanins of cv. Bovale sardo. * indicate significant difference at $\mathrm{P} \leq 0.05$ and $n$ s refers to non-significant differences

\begin{tabular}{|c|c|c|c|c|c|c|c|}
\hline \multirow{2}{*}{\multicolumn{2}{|c|}{$\begin{array}{c}\text { Anthocyanins } \\
(\%)\end{array}$}} & \multicolumn{3}{|c|}{2009} & \multicolumn{3}{|c|}{2010} \\
\hline & & $\begin{array}{c}500 \\
\mathrm{~m}\end{array}$ & $\begin{array}{c}700 \\
\mathrm{~m}\end{array}$ & sig. & $\begin{array}{c}500 \\
\mathrm{~m}\end{array}$ & $\begin{array}{c}700 \\
\mathrm{~m}\end{array}$ & sig. \\
\hline \multirow{6}{*}{ 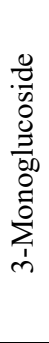 } & Delphinidin & 8.2 & 8.8 & ns & 11.6 & 10.9 & ns \\
\hline & Cyanidin & 1.6 & 1.7 & $\mathrm{~ns}$ & 3 & 4.2 & ns \\
\hline & Petunidin & 10.5 & 11.1 & $\mathrm{~ns}$ & 12.8 & 13.2 & ns \\
\hline & Peonidin & 2.6 & 3 & ns & 3.9 & 6.5 & $*$ \\
\hline & Malvidin & 38.4 & 43.1 & ns & 42.9 & 45.6 & $\mathrm{~ns}$ \\
\hline & Total & 61.3 & 67.7 & & 74.2 & 80.4 & \\
\hline \multirow{6}{*}{ 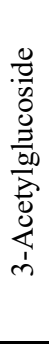 } & Delphinidin & n.d. & n.d. & & n.d. & n.d. & \\
\hline & Cyanidin & n.d. & n.d. & & n.d. & n.d. & \\
\hline & Petunidin & 0.1 & 0 & ns & n.d. & n.d. & \\
\hline & Peonidin & 0.2 & 0.3 & ns & 0.3 & 0.2 & $\mathrm{~ns}$ \\
\hline & Malvidin & 7.3 & 6.2 & $\mathrm{~ns}$ & 5.4 & 3.4 & $*$ \\
\hline & Total & 7.6 & 6.5 & & 5.7 & 3.6 & \\
\hline \multirow{6}{*}{ 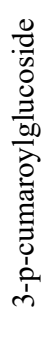 } & Delphinidin & n.d. & n.d. & & n.d. & n.d. & \\
\hline & Cyanidin & 1.1 & 1.3 & ns & 1.4 & 1.6 & ns \\
\hline & Petunidin & 0,4 & 0,5 & $\mathrm{~ns}$ & 0.3 & 0.1 & ns \\
\hline & Peonidin & 2 & 2.1 & ns & 1.6 & 1.7 & ns \\
\hline & Malvidin & 27.6 & 21.9 & $*$ & 16.8 & 12.6 & $*$ \\
\hline & Total & 31.1 & 25.8 & & 20.1 & 16 & \\
\hline
\end{tabular}

Farther, photosynthesis could be enhanced at high altitudes, due to an increased solar radiation and a reduced photorespiration. Mateus et al., [7] reported a positive role of altitude in enhancing the accumulation of flavonoids, especially anthocyanins and flavonols. Similar finding have been presented by Xing et al. [1] in Cabernet sauvignon cultivated in southwest China. Our data only partially confirm these previous works. In fact, although 
the greater altitude has not influenced the synthesis of the extractable anthocyanins but only the total ones (and only in the genetically richest variety, cv. Bovale sardo), the greater altitude has changed the relationship between acylated and non-acylated anthocyanins, promoting an increase in the non-acylated forms, as previous observed by Xing et al [1]. Based on experiments conducted on cv. Cannonau [21] in Sardinia, we can hypothesize that this increase was not forced by temperature variations between the two experimental areas, but rather by the effect of UV sunlight, in particular UV-B.

\section{Conclusions}

The results of our study showed that the recent relocation of the cultivation of the three varieties Cannonau, Monica and Bovale sardo, to higher altitudes, is allowing local grape growers to sustain viticultural production in areas until recently considered not particularly suitable for wine production. The three cultivars, blended together, take part in the composition of the Mandrolisai wine with a distinctive contribution from each cultivar. As expected, the effects of altitude on the qualitative characteristics of the grapes are variety-dependent. Specifically, the higher cultivation altitude promoted wines characterized by greater acidity and higher alcohol content, without any appreciable change in colour intensity.

\section{References}

1. R.R. Xing, F. He, H.L. Xiao, C.Q. Duan, Q.H. Pan. S. Afr. J. Enol. Vitic., 36, 1 (2015)

2. I. Rodriguez, J. Queijeiro, A. Masa, M. Vilanova. Proceeding of VIII InternatIonal terroir Congress. Soave, Italy (2010)

3. M. Stefanini, F. Iacono, L. De Micheli, D. Porro. Acta hortic. 388, 71-76 (1993)

4. M. Bertamini, E. Mescalchin, G. Bazzanella.. Vignevini, 26, 6, 82-95 (1999)

5. P. Storchi, G.B. Mattii. Atti V Giornate Scientifiche SOI, Italy (2000)

6. D. Nedelkowski, I. Semerdjieva, V. Roychev, T. Mokreva. Bulgarian Journal of Agricultural Science, 24 (2), 223-228 (2018)

7. N. Mateus, S. Proenca, P. Riberio, J.M. Machado, V. Cienc. Tecnol. Aliment. 3 (2), 102-110, (2001)

8. N. Mateus, J.M. Machado, V. De Freitas. J. Sci. Food Agric. 82, 1689-1695 (2002)

9. T.X. Yue, M. Chi, C.Z. Song, M.Y. Liu, J.F. Meng, Z.W. Zhang, M.H. Li. Int. J. Food Prop. 18, 1584-1596 (2015)

10. L. Mercenaro, A. Oliveira, M. Cocco, G. Nieddu. Acta hortic., 1188, 65-72 (2017)

11. L. Mercenaro, G. Nieddu, A. Porceddu, M. Pezzotti, S. Camiolo. Front. Plant Science, 8, 1-13 (2017)

12. F. Mattivi, A. Prast, G. Nicolini, L. Valenti.. Riv. Vitic. Enol. 2/3, 55-74 (2002)
13. R. Di Stefano, M.C. Cravero, N. Gentilini. L'enotecnico, 5, 83-89 (1989)

14. R. Di Stefano, M.C. Cravero. Rivista di Viticoltura e di Enologia, 2, 37-45 (1991)

15. L. Mercenaro, G. Usai, C. Fadda, G. Nieddu, A. Del Caro. S. Afr. J. Enol. Vitic., 37, 1 (2016)

16. L. Ponti, Q.A. Cossu, A.P. Gutierrez. Global change biology, 15 (12), 2847-2884 (2009)

17. L. Mariani. Accademia italiana della vite e del vino. Bollettino 4, atto 66, n. 278 (2016)

18. H. R. Schultz. Journal of wine economy, 11, 1 (2016)

19. T. Lino, P. Scafidi, M.G. Barbagallo. Quad. Vitic. Enol. Univ. Torino, 29, 113-124, ISBN 1970-6545 (2007)

20. D. Tomasi, F. Gaiotti, O. Locci, E. Goddi. Le terre e le vigne del Cannonau di Jerzu. ISBN 978-88-97081-180 (2012)

21. A. Fernandes de Oliveira, G. Nieddu. Austr. J. Grape Wine R, 22 (1), 96-104 (2016) 